\title{
An unusual presentation of glomeruloid hemangioma in a patient with VHL syndrome: A case report and review of literature
}

\author{
Leomar Y. Ballester ${ }^{1}$, Phyu P. Aung ${ }^{1 *}$, Jin-Ping Lai ${ }^{1}$, John J. DiGiovanna ${ }^{3}$, Zied Abdullaev', \\ Svetlana Pack ${ }^{1}$, W. Marston Linehan ${ }^{2}$, Jere B. Stern ${ }^{1}$, Peter A. Pinto ${ }^{2}$, Chyi-Chia R. Lee ${ }^{1 \#}$ \\ ${ }^{1}$ Laboratory of Pathology, National Cancer Institute, National Institute of Health, Bethesda, USA \\ ${ }^{2}$ Urologic Oncology Branch, National Cancer Institute, National Institute of Health, Bethesda, USA \\ ${ }^{3}$ Dermatology Branch, National Cancer Institute, National Institute of Health, Bethesda, USA \\ Email: "leechy@mail.nih.gov
}

Received 25 February 2013; revised 26 March 2013; accepted 3 April 2013

Copyright (c) 2013 Leomar Y. Ballester et al. This is an open access article distributed under the Creative Commons Attribution License, which permits unrestricted use, distribution, and reproduction in any medium, provided the original work is properly cited.

\begin{abstract}
Von Hippel-Lindau (VHL) is an inherited neoplasia syndrome caused by inactivation of the VHL tumor suppressor gene, characterized by the development of sporadic clear cell renal carcinoma, pheochromocytomas, retinal angioma, pancreatic cysts, and CNS hemangioblastomas. Glomeruloid hemangioma is a vascular lesion, previously considered to be specifically associated with POEMS (polyneuropathy, organomegaly, endocrinopathy/edema, M-protein and skin abnormalities) syndrome. However, there are reports of solitary glomeruloid hemangioma in patients without POEMS syndrome. We report the case of a 39-year-old male with VHL disease, with known bilateral clear cell renal carcinomas, CNS hemangioblastoma and pancreatic cysts. The patient presented with a $0.35 \mathrm{~cm}$ red papule on the left lateral neck, which was easily irritated, and bleed frequently. Histopathologically, there were irregular areas of ectatic vascular channels of small capillaries, resembling renal glomeruli, surrounded by actin-positive pericytes, within the dermis. These findings were consistent with a glomeruloid hemangioma. Fluorescent in-situ hybridization studies confirmed a deletion in the 3p25.3 region. As per clinical tests, no evidence of POEMS syndrome was found in this patient. Only six reports of glomeruloid hemangioma have been previously reported in patients without POEMS syndrome and this constitutes the first report of glomeruloid hemangioma in a patient with VHL.
\end{abstract}

\footnotetext{
"These two authors contributed equally to this manuscript.

${ }^{*}$ Corresponding author.
}

Keywords: Von Hippel-Lindau (VHL); Glomeruloid Hemangioma; POEMS; Immunohistochemical Stain; Fluorescent in Situ Hybridization (FISH) Analysis

\section{INTRODUCTION}

Von Hippel-Lindau (VHL) disease is a rare autosomal dominant hereditary disorder with variable expression and multi-organ manifestations including hemangioblastoma of the retina and central nervous system, pancreatic cysts, pheochromocytoma/paraganglioma, renal cysts and renal cell carcinoma (RCC) [1]. The responsible gene of VHL disease was identified in 1993 on the short arm of chromosome 3 [2-4].

POEMS (polyneuropathy, organomegaly, endocrinepathy/edema, M-protein and skin abnormalities) syndrome, which was first reported in 1968, is a multisystem disease [5]. Glomeruloid hemangiomas are benign vascular tumors comprised by dilated vascular spaces filled by aggregates of small capillary vessels, morphologically resembling renal glomeruli. This lesion was first introduced as a distinctive vascular proliferation occurring in patients with POEMS syndrome [6].

\section{CASE REPORT}

Our patient, who was diagnosed with VHL in 2002, underwent multiple surgeries for clear cell renal cell carcinoma, cerebellar and spinal hemangioblastomas, as well as pancreatic cysts. He was treated with Vandetanib since November 2010 and developed a phototoxic reaction to this drug. His family history is significant for VHL syndrome in his mother and grandfather. Both of them passed away due to renal cell carcinoma with kidney failure. He presented to the Dermatology Clinic at the 
National Institutes of Health for a follow-up evaluation of the phototoxic reaction, with generalized hyperpigmentation (related to treatment with ZD6474/vandetanib), which developed two months prior. At this time he complained of a skin lesion on the neck for two weeks, which was easily irritated and bled frequently. On physical examination, the lesion was a $0.35 \mathrm{~cm}$ pink, scaly papule on the left lateral neck (Figure 1(A)). Clinically, the lesion had features suspicious for angioma or skin cancer. No other cutaneous lesions were evident.

A biopsy taken from the papule showed hyperkeratosis with focal destruction of basal epidermal layers and a band-like lymphohistiocytic infiltrate in the upper dermis. The reticular dermis revealed closely arranged, dilated irregular-shaped vascular spaces, containing capillaries with nodular manner resembling renal glomeruli (Figures 1(B) and (C)). Histologic features diagnostic of malignancy, such as increased mitosis and necrosis, were not observed. The histophenotypic findings were consistent with a glomeruloid hemangioma. No evidence of POEMS was found on physical examination or multiple laboratory and imaging studies.

VHL disease is caused by mutations in the VHL gene on chromosome the (p) arm of chromosome 3 (3p25.3). Fluorescent in-situ hybridization studies using the CEP3 centromere probe for chromosome 3 and the VHL probe, showed deletion of the region containing the VHL gene (Figure 2), confirming the diagnosis of VHL in this patient.

\subsection{FISH Analysis of the VHL Gene Deletion on Paraffin-Embedded Hemangioma Tissue Sections}

For tumor interphase FISH analysis, BAC clone RP11-438J1 (210kB) including the entire VHL gene from the 3p25.3 region was used. The VHL BAC DNA probe labeled by SpectrumOrange was purchased from Empire Genomics (Buffalo, NY). Centromere enumeration probe for chromosome 3 (CEP3) labeled with SpectrumGreen was purchased from (Abbott Molecular, Chicago, IL). FISH assays were performed on 5-micron Formalin Fixed Paraffin Embedded (FFPE) tumor sections using laboratory standardized protocol with slight modification [7]. A total of minimum 100 nuclei were
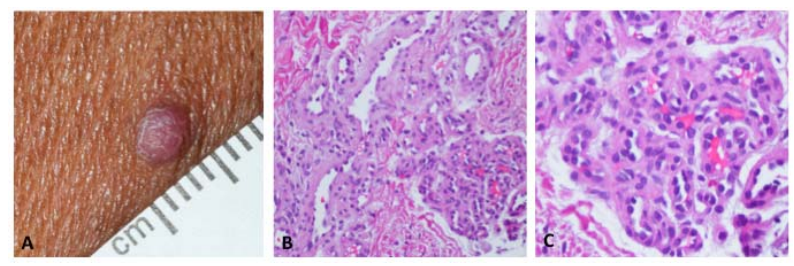

Figure 1. Clinical image of the scaly, pink papule on left lateral neck (A); H\&E stained section at 200× magnification (B); $\mathrm{H} \& \mathrm{E}$ stained section at $400 \times$ magnification (C).

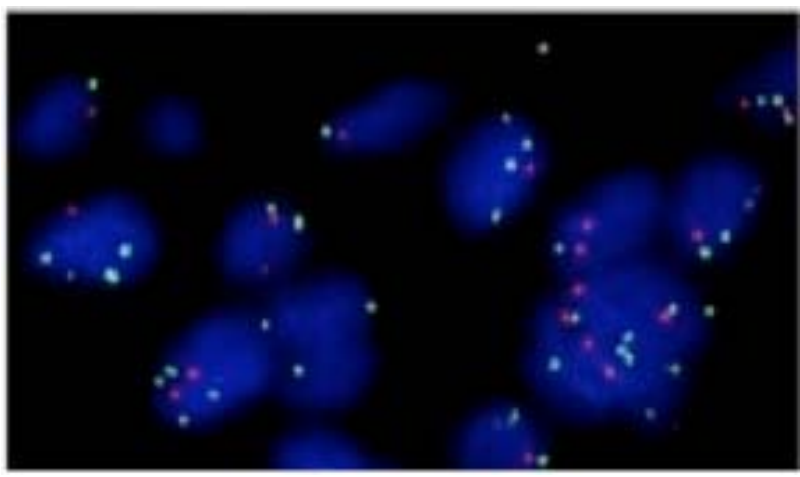

Figure 2. Dual-color FISH showing loss of the VHL gene copy (Red fluorescence signal) in the tumor cells compared to the control Chromosome 3 centromeric probe (Green fluorescence signals). Ratio of red:green $<0.8$.

scored for each specimen.

All margins, column widths, line spaces, and text fonts are prescribed; please do not alter them. You may note peculiarities. For example, the head margin in this template measures proportionately more than is customary. This measurement and others are deliberate, using specifications that anticipate your paper as one part of the entire journals, and not as an independent document. Please do not revise any of the current designations.

\section{DISCUSSION}

There are numerous nonspecific cutaneous manifestations in POEMS syndrome [8]. Multiple angiomas can occur in $26 \%$ of the patients with POEMS syndrome $[9,10]$.

VHL results from a mutation in the Von Hippel-Lindau tumor suppressor gene on chromosome 3p25.3. In VHL, the main manifestations are angiomatosis, hemangioblastoma, pheochromocytoma, renal cysts, renal cell carcinoma, pancreatic cysts (pancreatic serous cystadenoma) and café au lait spots [11]. Our patient developed diffuse hyperpigmentation due to photosensitivity associated with Vandetanib (ZD6474) therapy, an inhibitor of epidermal growth factor receptor, vascular endothelial growth factor receptor, and the RET (rearranged during transfection) kinases. Hyperpigmentation due to photosensitivity with Vandetanib therapy has been previously reported by Kong and coworkers [12].

To the best of our knowledge, there is no report of glomeruloid hemangiomas in VHL patients. Less than 25 cases of glomeruloid hemangioma in POEMS syndrome have been reported and this lesion was considered to be a dermatopathologic marker of POEMS syndrome. However, in the literature, there are six reports of glomeruloid hemangioma in patients without POEMS (summarized in Table 1) [13-18]. The average age for this group of patients is 57 years old (range: 29 - 86) with a male to female ratio is $7: 3$. 
Table 1. Summary of reported cases with glomeruloid hemangioma in the patients without POEMS syndrome.

\begin{tabular}{|c|c|c|c|c|c|c|}
\hline Case & Age (yr) & Gender & Number of lesion & Anatomic location & Underlying diseases & Reference \\
\hline 1 & 82 & $\mathrm{~F}$ & Solitary & Uterus & $\begin{array}{l}\text { Breast and endometrial } \\
\text { carcinomas }\end{array}$ & Giner et al. [13] \\
\hline 2 & 78 & M & Solitary & Scalp & $\begin{array}{l}\text { Hypertension, and bilateral } \\
\text { carpal tunnel syndrome }\end{array}$ & González-Guerra et al. [14] \\
\hline 3 & 50 & M & Solitary & Lateral neck & Hypertension and ${ }^{\wedge}$ DM type 2 & Lee et al. [15] \\
\hline 4 & 78 & $\mathrm{~F}$ & Solitary & Cheek & Hypertension and ${ }^{\wedge}$ DM type 2 & \\
\hline 5 & 33 & $\mathrm{~F}$ & Solitary & Unknown & None & Forman et al. [16] \\
\hline 6 & 29 & M & Solitary & Unknown & None & \\
\hline 7 & 53 & M & Solitary & Unknown & None & \\
\hline 8 & 46 & M & Multiple & Trunk & None & Piña-Oviedo et al. [17] \\
\hline 9 & 86 & M & Solitary & Face & $\begin{array}{l}\text { Hypertension, DM type } 2 \text { and } \\
\text { chronic bronchitis }\end{array}$ & Vélez et al. [18] \\
\hline 10 & 39 & M & Solitary & Lateral neck & "VHL & Current case \\
\hline
\end{tabular}

*VHL: Von Hippel-Lindau (VHL) syndrome. ${ }^{\wedge}$ DM type 2: Diabetes mellitus type 2.

The histogenesis of glomeruloid hemangiomas remains unclear. Studies have postulated that it is probably due to reactive endothelial proliferation and the overproduction of vascular endothelial growth factor 6 [19]. Eosinophilic globules, within the cytoplasm of some endothelial and stromal cells have been reported in glomeruloid hemangiomas. It has been postulated that the PAS-positive cytoplasmic material of endothelial and plump cells might represent immunoglobulins. In our case, a polytypic pattern of light chain immunoglobulins (kappa and lambda) is seen in PAS-positive hyaline globules containing cells (data not shown), as previously reported by Chan et al. All endothelial cells in our case are positive for CD31 and CD34 (data not shown).

Suurmeijer described that immunostaining of basement membrane for collagen type IV highlighted discriminating features between papillary hemangiomas (thin) and glomeruloid hemangiomas (thick) [20]. The immunostain of collagen type IV in our case showed thick basement membrane-like matrix enveloping pericytes (data not shown) as previously described in glomeruloid hemangiomas.

In our case, the lesion is single and developed in a patient with VHL disease. Although angiomatosis in several organs is one of the features of VHL syndrome, there has been no report of glomeruloid hemangioma in patients with VHL. This report further suggests that glomeruloid hemangioma is not necessarily a marker of POEMS and can also be seen in the patients with VHL syndrome.

\section{REFERENCES}

[1] Lonser, R.R., Glenn, G.M., Walther, M., Chew, E.Y., Libutti, S.K., Linehan, W.M. and Oldfield, E.H. (2003) Von Hippel-Lindau disease. Lancet, 361, 2059-2067.

\section{doi:10.1016/S0140-6736(03)13643-4}

[2] Gnarra, J.R., Glenn, G.M., Latif, F., Anglard, P., Lerman, M.I., Zbar, B. and Linehan, W.M. (1993) Molecular genetic studies of sporadic and familial renal cell carcinoma. Urologic Clinics of North America, 20, 207-216.

[3] Latif, F., Tory, K., Gnarra, J., Yao, M., Duh, F.M., Orcutt, M.L., Stackhouse, T., Kuzmin, I., Modi, W. and Geil, L. (1993) Identification of the von Hippel-Lindau disease tumor suppressor gene. Science, 260, 1317-1320. doi:10.1126/science.8493574

[4] Neumann, H.P and Wiestler, O.D. (1991) Clustering of features of von Hippel-Lindau syndrome: Evidence for a complex genetic locus. Lancet, 337, 1052-1054. doi:10.1016/0140-6736(91)91705-Y

[5] Shimpo S. (1968) Solitary myeloma causing polyneuritis and endocrine disturbances. Japanese Journal of Clinical Medicine, 26, 2444.

[6] Chan, J.K., Fletcher, C.D., Hicklin, G.A. and Rosai, J. (1990) Glomeruloid hemangioma: A distinctive cutaneous lesion of multicentric Castleman's disease associated with POEMS syndrome. The American Journal of Surgical Pathology, 14, 1036. doi:10.1097/00000478-199011000-00005

[7] Pack, S.D. and Zhuang Z. (2001) Fluorescence in situ hybridization: Application in cancer research and clinical diagnostics. Methods in Molecular Medicine, 50, 35-50.

[8] Kishimoto, S., Takenaka, H., Shibagaki, R., Noda, Y., Yakamoto, M. and Yasuno, H. (2000) Glomeruloid hemangioma in POEMS syndrome shows two different immunophenotypic endothelial cells. Journal of Cutaneous Pathology, 27, 87. doi:10.1034/j.1600-0560.2000.027002087.x

[9] Zea-Mendoza, A., Alonso-Ruiz, A., García-Vadillo, A., Moreno-Caparrós, A. and Beltrán-Gutierrez, J. (1984) POEMS syndrome with neuroarthropathy and nodular regenerative hyperplasia of the liver. Arthritis \& Rheumatism, 27, 1053. doi:10.1002/art.1780270914 
[10] Takatsuki, K. and Sanada, I. (1983) Plasma cell dyscrasia with polyneuropathy, organomegaly, and endocrine disorder: clinical and laboratory features of 109 cases. Japanese Journal of Clinical Oncology, 13, 543.

[11] Wong, W.T., Agrón, E., Coleman, H.R., Reed, G.F., Csaky, K., Peterson, J., Glenn, G., Linehan, W.M., Albert, P. and Chew, E.Y. (2007) Genotype-phenotype correlation in von Hippel-Lindaudisease with retinal angiomatosis. Archives of ophthalmology, 125, 239-245. doi:10.1001/archopht.125.2.239

[12] Kong, H.H, Fine, H.A., Stern, J.B. and Turner, M.L. (2009) Cutaneous pigmentation after photosensitivity induced by vandetanib therapy. Archives of Dermatology, 145, 923-925. doi:10.1001/archdermatol.2009.177

[13] Giner, F., Compañ, A. and Monteagudo, C. (2012) Uterine glomeruloid hemangioma in a patient without POEMS syndrome. International Journal of Surgical Pathology, 20, 407-410. doi:10.1177/1066896911429297

[14] González-Guerra, E., Haro, M.R., Fariña, M.C., Martín, L., Manzarbeitia, L. and Requena, L. (2009) Glomeruloid haemangioma is not always associated with POEMS syndrome. Clinical and Experimental Dermatology, 34, 800-803. doi:10.1111/j.1365-2230.2008.02997.x

[15] Lee, H., Meier, F.A., Ma, C.K., Ormsby, A.H. and Lee, M.W. (2008) Eosinophilic globules in 3 cases of glomeruloid hemangioma of the head and neck: A characteristic offering more evidence for thanatosomes with or without POEMS. The American Journal of Dermatopathology, 30, 539-544. doi:10.1097/DAD.0b013e318182c800

[16] Forman, S.B., Tyler, W.B., Ferringer, T.C. and Elston, D.M. (2007) Glomeruloid hemangiomas without POEMS syndrome: series of three cases. Journal of Cutaneous Pathology, 34, 956-957. doi:10.1111/j.1600-0560.2007.00742.x

[17] Piña-Oviedo, S., López-Patiño, S. and Ortiz-Hidalgo, C. (2006) Glomeruloid hemangiomas localized to the skin of the trunk with no clinical features of POEMS syndrome. International Journal of Dermatology, 45, 1449-1450. doi:10.1111/j.1365-4632.2006.03187.x

[18] Vélez, D., Delgado-Jiménez, Y. and Fraga, J. (2005) Solitary glomeruloid haemangioma without POEMS syndrome. Journal of Cutaneous Pathology, 32, 449-452. doi:10.1111/j.0303-6987.2005.00353.x

[19] Gherardi, R., Belec, L., Soubrier, M., Malapert, D., Zuber, M., Viard, J.P., Intrator, L., Degos, J.D., and Authier, F.J. (1996) Overproduction of proinflammatory cytokines imbalanced by their antagonists in POEMS syndrome. Blood, 87, 1458.

[20] Suurmeijer, A.J. (2010) Papillary hemangiomas and glomeruloid hemangiomas are distinct clinicopathological entities. International Journal of Surgical Pathology, 18, 48-54. doi:10.1177/1066896908323504 